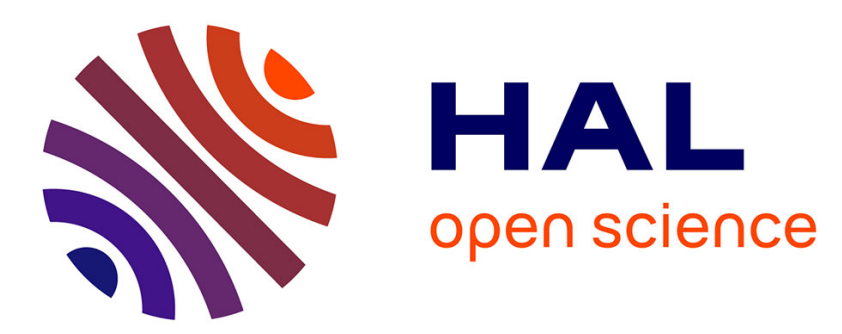

\title{
Modeling Ductile Fracture of Al Alloys in Relation with Statistical Distribution of Second Phase Particles
}

\author{
Philippe Achon, Jean-Christophe Ehrstrom, André Pineau
}

\section{To cite this version:}

Philippe Achon, Jean-Christophe Ehrstrom, André Pineau. Modeling Ductile Fracture of Al Alloys in Relation with Statistical Distribution of Second Phase Particles. Journal de Physique IV Proceedings, 1996, 06 (C6), pp.C6-3-C6-12. 10.1051/jp4:1996601 • jpa-00254429

\section{HAL Id: jpa-00254429 https://hal.science/jpa-00254429}

Submitted on 1 Jan 1996

HAL is a multi-disciplinary open access archive for the deposit and dissemination of scientific research documents, whether they are published or not. The documents may come from teaching and research institutions in France or abroad, or from public or private research centers.
L'archive ouverte pluridisciplinaire HAL, est destinée au dépôt et à la diffusion de documents scientifiques de niveau recherche, publiés ou non, émanant des établissements d'enseignement et de recherche français ou étrangers, des laboratoires publics ou privés. 


\title{
Modeling Ductile Fracture of Al Alloys in Relation with Statistical Distribution of Second Phase Particles
}

\author{
Ph. Achon*,1, J.C. Ehrstrom** and A. Pineau* \\ * Centre des Matériaux, Ecole des Mines, URA 866 du CNRS, BP. 87, 91003 Evry cedex, France \\ ** Centre de Recherches Pechiney, BP. 27, 38340 Voreppe, France
}

\begin{abstract}
Fracture toughness tests have been carried out on two Al alloys ( 7075 and 7475$)$ containing different amounts of Fe and Si. These materials were tested in T3, T6 and T7 conditions, along six orientations (LT, LS, TL, TS, SI and ST). Large variations in the fracture toughness (20-60 MPa $\sqrt{\mathrm{m})}$ were measured. Mechanical tests on notched specimens were also performed to determine the influence of stress triaxiality ratio on ductility. These specimens were calculated by finite element method. Quantitative metallography was largely used to measure the volume fraction of intermetallic particles $\left(\mathrm{Mg}_{2} \mathrm{Si}\right.$ and Fe-rich precipitates) and the statistical distribution of these particles. The Gurson potential is used to interpret these test resulls carried out on volume elements and on cracked specimens. It is shown that the ductility of notched specimens and the measured variations in fracture toughness can be interpreted with the Gurson potential provided that the non homogeneous distribution of intermetallic particles is taken into account. A model has been developed to relate the toughness of the alloys to the yield strength, the critical void growth rate calculated on notched specimen from Rice and Tracey equation and to the mean distance between the clusters of second phase particles.
\end{abstract}

\section{INTRODUCTION}

It is well established that the fracture toughness of high strength Al alloys is largely dependent on their composition and heat treatments. In particular their contents in residual elements, mainly $\mathrm{Fe}$ and $\mathrm{Si}$, are known to have a strong effect on the ductility of these materials. It is also well known that the toughness of Al alloy plates is strongly anisotropic. However very few detailed studies have been made to model the toughness of these materials in relation with their microstructure, in particular the distribution of secondphase iron and $\mathrm{Mg}_{2}$ si particles which initiate ductile fracture [1-3]. This situation is a little surprizing since this is clearly a research field of interest for the application of the local approach to fracture. The main aim of the present study was therefore an attempt to fill in this gap. Two materials with widely different contents in $\mathrm{Fe}$ and $\mathrm{Si}$ were selected. Fracture toughness tests along different orientations were performed on these materials which were given three heat treatments (T3,T6 and T7). In addition specific mechanical tests on notched specimens and detailed metallographical observations were made to test the validity of a model for ductile fracture which was proposed previously for the ductile fracture of low alloy steels [4-8].

\section{MATERIALS AND EXPERIMENTAL PROCEDURES}

The materials investigated were hot-rolled commercial $\mathrm{Al}-6.7 \mathrm{Zn}-2.50 \mathrm{Mg}-1.50 \mathrm{Cu}$ alloy plates with a thickness of $50 \mathrm{~mm}$. Their composition is given in Table 1. Alloy 7075 contained a much higher content in $\mathrm{Fe}$ and Si compared to alloy 7475. These elements are responsible for the formation of relatively large intermetallic phases of $\mathrm{Mg}_{2} \mathrm{Si}$ and $\mathrm{Al}_{7} \mathrm{Cu}_{2} \mathrm{Fe}+\mathrm{Al}_{23} \mathrm{CuFe}_{4}$, respectively. An example showing the inhomogeneity in the distribution of these phases observed in the LS plane is given in Fig.1. Both materials were investigated in three conditions : (i) Aged at room temperature (T351), (ii) Peak aged : $120^{\circ} \mathrm{C}-24$ hours (T651), and (iii) Overaged : $105^{\circ} \mathrm{C}-6$ hours $+160^{\circ} \mathrm{C}-24$ hours (T7351). The grain microstructure of both alloys was unrecrystallized with a pancake shape $\left(\approx 1 \times 04 \times 0.05 \mathrm{~mm}^{3}\right)$. The materials were strongly textured with two main components : $\{110\}<112>$ brass and $S\{123\}<634>$.

\begin{tabular}{||c|c|c|c|c|c|c|c|c|}
\hline Ailloy & $\mathbf{S i}$ & $\mathbf{F e}$ & $\mathbf{M n}$ & $\mathbf{T i}$ & $\mathbf{C r}$ & $\mathbf{C u}$ & $\overline{\mathbf{M g}}$ & $\mathbf{Z n}$ \\
\hline 7075 & 0.070 & 0.180 & 0.047 & 0.020 & 0.24 & 1.48 & 2.64 & 5.71 \\
\hline 7475 & 0.039 & 0.050 & 0.022 & 0.017 & 0.21 & 1.52 & 2.33 & 5.85 \\
\hline
\end{tabular}

Table 1 - Chemical composition (wt \%)

$\overline{1}$ Now with Institut de Soudure, Centre A. Leroy, 57365 Ennery, France 


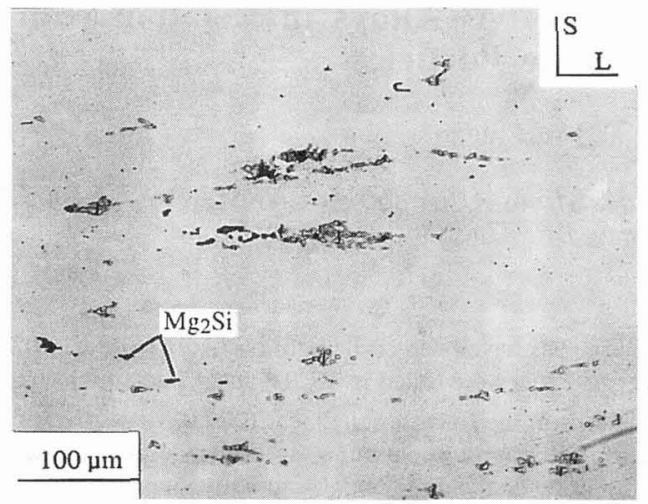

Figure 1: Optical micrograph illustrating the distribution of $\mathrm{Mg}_{2} \mathrm{Si}$ and $\mathrm{Fe}$ rich particles in 7075 alloy.

The tensile properties of these materials tested along the three main rolling directions $(\mathrm{L}, \mathrm{T}, \mathrm{S})$ are given in Table 2 where it is noticed that the tensile strength measured in the short tranverse direction is lower than that along the $\mathrm{L}$ and $\mathrm{T}$ orientations. The tensile ductility of alloy 7475 is hetter than that of alloy 7075 , as expected. In both alloys, the work-hardening exponent, $n\left(\sigma=k \varepsilon^{n}\right)$ was found to be essentially dependent on the heat-treatment : $\mathrm{n}=0.17,0.10,0.11$ in the $\mathrm{T} 3, \mathrm{~T} 6$ and $\mathrm{T} 7$ conditions, respectively.

\begin{tabular}{|c|c|c|c|c|c|c|}
\hline Alloy & Orientation & $\begin{array}{c}\text { Heat } \\
\text { Treatment }\end{array}$ & $\begin{array}{r}\text { Rpo.2 } \\
\text { (MPa) }\end{array}$ & $\begin{array}{c}\text { UTS } \\
\text { (MPa) }\end{array}$ & $\stackrel{A}{(\%)}$ & $\sum_{(\boldsymbol{\%})}$ \\
\hline \multirow{3}{*}{7075} & $\mathrm{~L}$ & $\begin{array}{l}\text { T } 351 \\
\text { T 651 } \\
\text { T 7351 }\end{array}$ & $\begin{array}{l}450 \\
520 \\
451\end{array}$ & $\begin{array}{l}574 \\
589 \\
526\end{array}$ & $\begin{array}{c}9.6 \\
10.2 \\
8.4\end{array}$ & $\begin{array}{l}14 \\
15 \\
22\end{array}$ \\
\hline & $\mathrm{T}$ & $\begin{array}{l}\text { T 351 } \\
\text { T 651 } \\
\text { T 7351 } \\
\end{array}$ & $\begin{array}{l}403 \\
497 \\
440 \\
\end{array}$ & $\begin{array}{l}556 \\
570 \\
514\end{array}$ & $\begin{array}{l}10.1 \\
8.3 \\
8.2\end{array}$ & $\begin{array}{l}13 \\
13 \\
19\end{array}$ \\
\hline & $S$ & $\begin{array}{c}\text { T } 351 \\
\text { T 651 } \\
\text { T 7351 }\end{array}$ & $\begin{array}{l}349 \\
451 \\
414 \\
\end{array}$ & $\begin{array}{l}498 \\
534 \\
493 \\
\end{array}$ & $\begin{array}{l}6.3 \\
4.5 \\
5.4\end{array}$ & $\begin{array}{l}8 \\
7 \\
8 \\
\end{array}$ \\
\hline \multirow{3}{*}{7475} & $\mathrm{~L}$ & $\begin{array}{c}\text { T } 351 \\
\text { T } 651 \\
\text { T } 7351 \\
\end{array}$ & $\begin{array}{l}447 \\
523 \\
452 \\
\end{array}$ & $\begin{array}{l}578 \\
588 \\
519 \\
\end{array}$ & $\begin{array}{l}10.1 \\
11.5 \\
12.5 \\
\end{array}$ & $\begin{array}{l}15 \\
18 \\
34 \\
\end{array}$ \\
\hline & $\mathrm{T}$ & $\begin{array}{c}\text { T } 351 \\
\text { T } 651 \\
\text { T } 7351\end{array}$ & $\begin{array}{l}414 \\
506 \\
449\end{array}$ & $\begin{array}{l}565 \\
578 \\
514\end{array}$ & $\begin{array}{l}11.8 \\
11.8 \\
11.4\end{array}$ & $\begin{array}{l}15 \\
22 \\
38\end{array}$ \\
\hline & $S$ & $\begin{array}{c}\text { T 351 } \\
\text { T 651 } \\
\text { T 7351 }\end{array}$ & $\begin{array}{l}343 \\
447 \\
416\end{array}$ & $\begin{array}{l}523 \\
545 \\
504\end{array}$ & $\begin{array}{c}13.5 \\
10 \\
10.9\end{array}$ & $\begin{array}{l}19 \\
18 \\
20\end{array}$ \\
\hline
\end{tabular}

Table 2 - Mechanical Properties.

Axisymmetrically notched tensile specimens were tested in order to determine the effect of stress triaxiality ratio on ductile fracture. Full details concerning these tests are given elsewhere [9]. Three specimen geometries were tested with a minimum diameter, $\varnothing_{\mathrm{O}}$, of $10 \mathrm{~mm}$, a gauge diameter, $\emptyset_{\text {ext }}$ of 18 $\mathrm{mm}$ and a notch radius of $\mathrm{R}=10,4$ and $2 \mathrm{~mm}$. These dimensions were used for the specimens tested along the $L$ and $T$ directions. The same geometries but with reduced dimensions $\left(\emptyset_{0}=6 \mathrm{~mm}, \emptyset_{0}=10.8\right.$ $\mathrm{mm}, \mathrm{R}=6,2.4$ and $1.2 \mathrm{~mm}$ ) were used to test the materials along the $S$ direction. These specimens were modelled by finite element method.

Fracture toughness tests were carried out along 6 orientations : LT, LS, TL, TS, SL and ST. CT30 mm specimens were used for the LT, LS, TL and TS orientations, while CT $20 \mathrm{~mm}$ specimens were used for the two other orientations. In the T6 condition, in both materials, the test results could be interpreted in terms of valid $\mathrm{K}_{\mathrm{IC}}$, while in the two other conditions, $\mathrm{J}_{\mathrm{IC}}$ was measured according to ASTM E 813 standards. These values of $\mathrm{J}_{\mathrm{IC}}$ were converted into $\mathrm{K}_{\mathrm{IC}}$ by $\mathrm{K}_{\mathrm{IC}}=\left[\mathrm{E} \mathrm{J}_{\mathrm{IC}} /\left(1-\mathrm{v}^{2}\right)\right]^{1 / 2}$. 


\section{EXPERIMENTAL RESULTS}

\section{. Distribution of second phase particles}

Quantitative metallography was largely used to measure the distribution of $\mathrm{Mg}$ and Fe rich particles. The number of inclusions per unit area $\mathrm{Nai}(\mathrm{i}=\mathrm{L}, \mathrm{T}, \mathrm{S})$ and their size were measured on three section planes. The total number of particles per unit volume, Nv and the volume fraction, $f v$ were determined. The results of these measurements are given in Table 3 where it is observed that the volume fraction of intermetallic phases is about 3.5 times larger in 7075 alloy than in 7475 alloy.

\begin{tabular}{|c|c|c|c|c|}
\hline Alloy & & Fe rich particles & Mg2 Si & Total \\
\hline 7075 & $\begin{array}{c}\mathrm{f}_{\mathrm{v}}(\%) \\
\mathrm{N}_{\mathrm{V}}\left(10^{3} / \mathrm{mm}^{3}\right) \\
\operatorname{Size}\left(\mu \mathrm{m}^{3}\right)\end{array}$ & $\begin{array}{c}1.024 \\
148.3 \\
67 \times 4.8 \times 2.5\end{array}$ & $\begin{array}{c}0.166 \\
11 \\
14.4 \times 7.7 \times 3.5\end{array}$ & $\begin{array}{c}1.19 \\
159.3\end{array}$ \\
\hline 7475 & $\begin{array}{c}f_{v}(\%) \\
\mathrm{N}_{\mathrm{v}}\left(10^{3} / \mathrm{mm}^{3}\right) \\
\operatorname{Size}\left(\mu \mathrm{m}^{3}\right) \\
\end{array}$ & $\begin{array}{c}0.277 \\
71.1 \\
5.4 \times 5 \times 2.3\end{array}$ & $\begin{array}{c}0.066 \\
3.9 \\
11.5 \times 8.4 \times 3.8\end{array}$ & $\begin{array}{c}0.343 \\
75\end{array}$ \\
\hline
\end{tabular}

Table 3 - Iron rich and $\mathrm{Mg}_{2}$ Si particles in 7075 and 7475 alloys.

Metallographical techniques based on Voronoï cells and Delaunay triangulations were used to quantify these distributions of second phase particles [9]. Examples concerning 7075 alloy observed on two section planes are shown in Fig.2a and $b$. In these figures each point corresponds to a particle. The Delaunay triangulation technique was used to analyze the clustering effect of the particles, as observed in these figures. Full details are given elsewhere [9]. This analysis was used to determine the mean distance between the clusters and the volume fraction occupied by the clusters, defined as : $\sum \mathrm{a}_{\mathrm{i}} / \mathrm{S}$, where $\mathrm{a}_{\mathrm{i}}$ is the surface area occupied by the clusters in a section of area $S$. The results are given in Table 4.
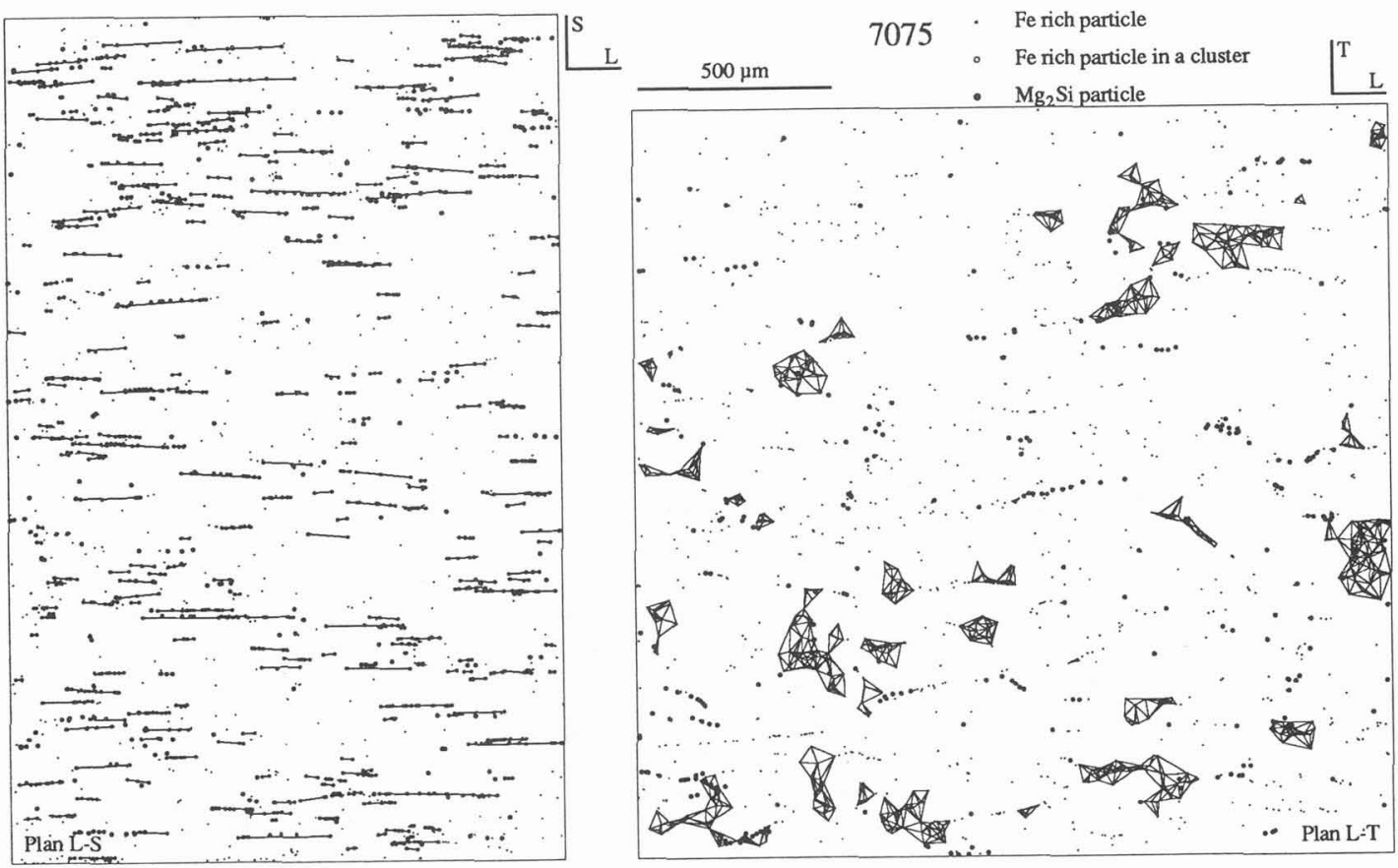

Figure 2: Distribution of second phase particles in 7075 alloy analyzed by quantitative metallography.

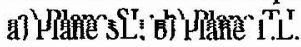




\begin{tabular}{||c|c|c|c|c|}
\hline Alloy & Clusters & \multicolumn{3}{|c|}{ Plane ; $\mathbf{i} \cdot \mathbf{j}$} \\
\hline & & LT & LS & TS \\
\hline \multirow{2}{*}{7075} & f clusters $(\%)$ & 5.2 & 2.0 & 1.9 \\
& $\lambda$ clusters $(\mu \mathrm{m})$ & 162.2 & 50.3 & 49.2 \\
\hline \multirow{2}{*}{7475} & f clusters $(\%)$ & 3.4 & 1.0 & 0.6 \\
& $\lambda$ clusters $(\mu \mathrm{m})$ & 180.2 & 78 & 79.1 \\
\hline
\end{tabular}

Table 4 - Volume fraction of clusters and mean distance between clusters in three sections. Alloys 7075 and 7475.

\section{. Mechanical tests on notched specimens}

The results of tensile tests performed on notched specimens are given in Fig.3. In this figure the variations of ductility defined as $\varepsilon=2 \log \emptyset_{0} / \emptyset_{R}$, where $\emptyset_{0}$ is the initial minimum diameter of the specimens and $\emptyset_{\mathrm{R}}$ the minimum diameter at failure, are plotted as a function of stress triaxiality ratio, $\sigma_{\mathrm{m}} / \sigma_{\mathrm{eq}}$, calculated from finite elements in the center of the minimum section of the notched specimens. In Fig.3, the results obtained on smooth tensile specimens are also included. Here it is worth noting that, in a number of circumstances, shear fracture along a plane oriented roughly at 45 degrees from the tensile axis was observed. This fracture mode occurred in all the tensile specimens, whatever the alloy and the heat-treatment, except in the specimens aligned along the $\mathbf{S}$ orientation for which the fracture plane was perpendicular to the tensile axis. In notched specimens this shear fracture mode was suppressed, in particular in the specimens containing small notches ( 4 and $2 \mathrm{~mm}$ ), except in T3 condition.
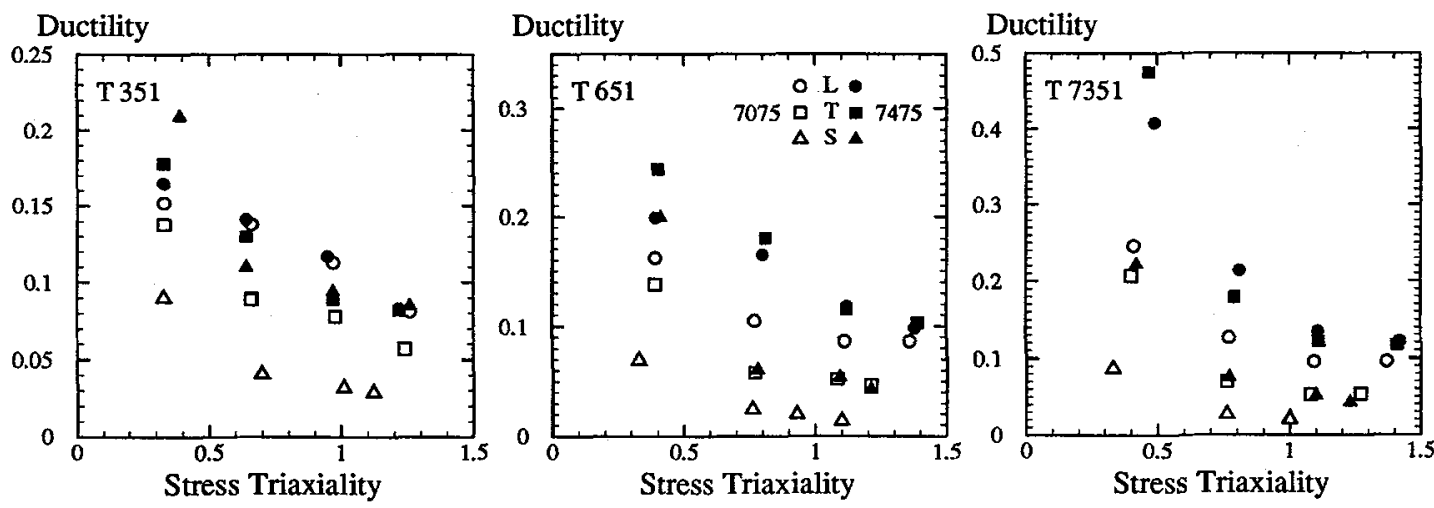

Figure 3: Variation of ductility measured on smooth and notched specimens as a function of stress triaxiality ratio. Alloys 7075 and 7475 tested in three conditions (T3, T6, T7) and along three orientations (L.T.S).

The results show that the ductility is a decreasing function of stress triaxiality ratio and of the volume fraction of second phase particles, as expected. Moreover it is noticed that $\varepsilon_{R L}>\varepsilon_{R T}>\varepsilon_{R S}$ when the same fracture mode occurs. In addition, the ductility is an increasing function of the work-hardening exponent, i.e., $\varepsilon_{\mathrm{RT} 3}>\varepsilon_{\mathrm{RT} 7}>\varepsilon_{\mathrm{RT}}$.

It is usually assumed that fracture takes place in volume elements when the void growth calculated, for instance, from Rice and Tracey expression [10] reaches a critical value, $\left(R / R_{0}\right)_{c}$, where $R o$ is the initial radius of the cavities initiating ductile fracture $[11,12]$. This assumption is all the more valid as the strain necessary to nucleate cavities is small, which is the situation observed in these materials [9]. The Rice and Tracey expression can be written as : 


$$
\mathrm{dR} / \mathrm{R}=0.283 \exp \left(3 \sigma_{\mathrm{m}} / 2 \sigma_{\mathrm{eq}}\right) . \mathrm{d} \varepsilon_{\mathrm{eq}}
$$

where $R$ is the size of the cavities initiated from inclusions, $\sigma_{m}$ the hydrostatic stress, $\sigma_{e q}$ the equivalent von Mises stress, and $d \varepsilon_{e q}$ the increment of equivalent strain. Eq.1 was integrated along the $\sigma-\varepsilon$ path experienced by the mesh elements in the notched specimens. The largest values for $\left(R / R_{0}\right)_{c}$ were found in the center of the $\rho=10$ and 4 notched geometries, while in the $\rho=2 \mathrm{~mm}$ specimens these maximum values were obtained at a location between the center and the notch throat. These calculations showed that the local ductility, $\varepsilon_{\mathrm{p}}$, thus defined, obeyed rather well the assumption of critical void growth, that is a straight line with a slope of $-3 / 2$ could be drawn in a diagram $L n \varepsilon_{\mathrm{p}}$ vs local values of $\sigma_{\mathrm{m}} / \sigma_{\mathrm{eq}}$ [9]. The calculated values of $\left(\mathrm{R} / \mathrm{R}_{\mathrm{O}}\right)_{\mathrm{c}}$ are given in Table 5 . These values are extremely low, especially in the $S$ orientation, compared to those usually reported in low alloy ferritic steels $[4,8]$. This reflects the qualitative difference in ductility between these materials, but a full account of these low values of critical void growth rate will be given in the following.

\begin{tabular}{||c|c|c|c|c|c|c|}
\hline Alloy & \multicolumn{3}{|c|}{$\mathbf{7 0 7 5}$} & \multicolumn{3}{|c|}{$\mathbf{7 4 7 5}$} \\
\hline Orientation & $\mathrm{T} 351$ & $\mathrm{~T} 651$ & $\mathrm{~T} 7351$ & $\mathrm{~T} 351$ & $\mathrm{~T} 651$ & $\mathrm{~T} 7351$ \\
\hline $\mathrm{L}$ & $1.105(1.20)$ & 1.10 & 1.11 & $1.115(1.30)$ & 1.13 & 1.18 \\
\hline $\mathrm{T}$ & $1.07(1.11)$ & 1.05 & 1.06 & $1.10(1.28)$ & 1.12 & 1.16 \\
\hline $\mathrm{S}$ & 1.03 & 1.02 & 1.02 & 1.09 & 1.05 & 1.06 \\
\hline
\end{tabular}

Table 5 - Critical void growth rate along 3 orientations in 7075 and 7475 alloys.

\section{- Fracture toughness tests}

The results of fracture toughness tests are shown in Fig. 4 where it is observed that alloy 7475 is much tougher than alloy 7075 , as expected. Moreover it is noted that $\mathrm{K}_{\mathrm{ICT} 3}>\mathrm{K}_{\mathrm{ICT} 7}>\mathrm{K}_{\mathrm{ICT}}$. It is also observed that the orientation has a strong influence on the fracture toughness : $\mathrm{K}_{\mathrm{IC}} \mathrm{L}-(\mathrm{TS})>\mathrm{K}_{\mathrm{IC}} \mathrm{T}$ $(\mathrm{LS})>\mathrm{K}_{\mathrm{IC}} \mathrm{S}-(\mathrm{LT})$.

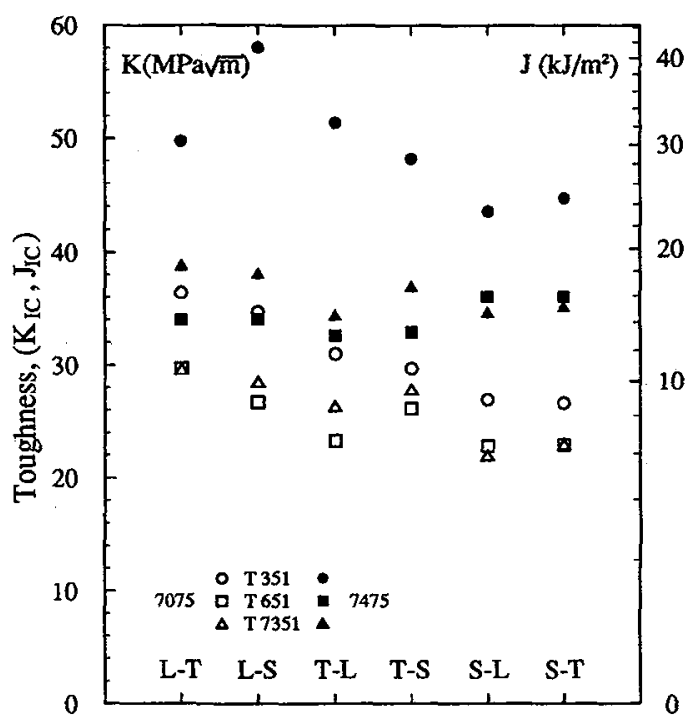

Figure 4: Alloys 7075 and 7475 tested along various orientations. Results of fracture toughness measurements. 


\section{MODELING OF FRACTURE TOUGHNESS}

The aim of this part is to model the large variations in fracture toughness measured in our materials through the use of the local approach to ductile fracture. The results of mechanical tests performed on notched specimens and the results of quantitative metallography will be used for this purpose. This model based on the mechanics of porous materials is firstly briefly presented. Preliminary results and other approaches have been presented elsewhere [13-15].

\section{- Mechanics of porous materials}

Many studies have been devoted, over the past decade, to model the softening effect produced by growing cavities and void coalescence, using the mechanics of porous materials. In these models, the plastic flow potential is dependent on cavity volume fraction $[6,16,17]$. It is beyond this paper to review all the existing theories but, instead, to show how these theories can be used to model ductile fracture of our alloys and to take into account the non inhomogeneity in the distribution of second phase particles initiating ductile fracture. Here we refer only to the Gurson-Tvergaard (GT) model. In the GT potential, the yield criterion is written as [16] :

$$
\sigma_{\mathrm{eq}}^{2} / \mathrm{Y}^{2}+2 \mathrm{q}_{1} \mathrm{f} \cosh \left(3 \mathrm{q}_{2} \sigma_{\mathrm{m}} / 2 \mathrm{Y}\right)-1-\mathrm{q}_{3} \mathrm{f}^{2}=0
$$

where $\mathrm{Y}$ is the flow strength of the undamaged matrix and $\mathrm{f}$ is the volume fraction of cavities. It was shown that $q_{1} \sim 1.50, q_{2} \sim 1, q_{3}=q_{1}^{2}$ [16]. Perrin and Leblond [18] using a self consistent scheme showed that $\mathrm{q}_{1}=4 / \mathrm{e}=1.47$. For small volume fractions, Eq. 2 can be simplified as :

$$
\sigma_{\text {eq }}=\sqrt{(3 / 2) s_{i j} s_{i j}}=Y\left[1-0.50 f \exp \left(3 \sigma_{\mathrm{m}} / 2 \mathrm{Y}\right)\right]
$$

In this expression the softening effect due to the presence of cavities appears clearly to be an increasing function of stress triaxiality ratio, as expected. The associated increment in cavity volume fraction is given by :

$$
\mathrm{d} \varepsilon_{\mathrm{ii}}=\mathrm{df} /(1-\mathrm{f})=0.75 \mathrm{f} \exp \left(3 \sigma_{\mathrm{m}} / 2 \mathrm{Y}\right) . \mathrm{d} \varepsilon_{\mathrm{eq}}
$$

which is very similar to Eq.1.

The application of the GT potential was reviewed by Needleman [19]. In the simulation of ductile fracture of a material in which the cavities are homogeneously distributed, it was shown that this model largely overestimated the observed ductility. An accelerating function $\mathrm{f}^{*}$ was introduced by Tvergaard and Needleman [20] to simulate the effect of void coalescence. Initially $\mathrm{f}^{*}=\mathrm{f}$, but, at some crititical volume fraction, $\mathrm{f}_{\mathrm{c}}, \mathrm{f}^{*}$ is written as :

$$
f^{*}=f_{c}+\delta\left(f-f_{c}\right)
$$

where $\delta$ is an accelerating factor. This approach is therefore to some extent similar to the $\left(R / R_{0}\right)_{c}$ criterion which was introduced previously. Both approaches can be considered as "black boxes" in the absence of a proper account of cavity distribution. The effect of a non-uniform distribution of cavities was analyzed numerically by Becker [21] using the same modification of the G.T. potential. This author showed that a fracture criterion based on a critical void growth rate which is only weakly dependent on stress triaxiality ratio was appropriate. This conclusion reinforces the soundness of the $\left(R / R_{0}\right)_{c}$ criterion but gives no insight into a deeper account of the second phase distribution since fracture is essentially assumed to take place when $f$ reaches the ascribed value of $\mathrm{fc}$ and not the value of $\mathrm{fu}=1 / \mathrm{q} 1$ predicted from Eq.2. 


\section{. Clusters and ductile fracture of notched specimens}

Mudry [4] used also the GT potential to model the ductile fracture of low alloy steels, but without introducing the above accelerating factor. The basis of his model is schematically shown in Fig. 5 where the $\sigma-\varepsilon$ curve of the undamaged matrix $\left(f_{O i}\right)$ is compared to that corresponding to a given value of the initial volume fraction of cavities (for instance $0.75 \%$ ). Fracture of a notched specimen is assumed to take place if there is a non-vanishing probability of finding a volume element for which the local volume fraction, $f_{0}$ is such that the associated $\sigma-\varepsilon$ curve reaches a maximum (see also [22]). The macroscopic ductility is then calculated as indicated in Fig.5, assuming that the volume element bears the same stress as the matrix. The same type of calculation could be applied to volume elements bearing the same strain [13]. In the present study only the first assumption was used to calculate from the G.T. potential the corresponding values of initial volume fraction of cavities ( $\mathrm{f}$ Gurson).

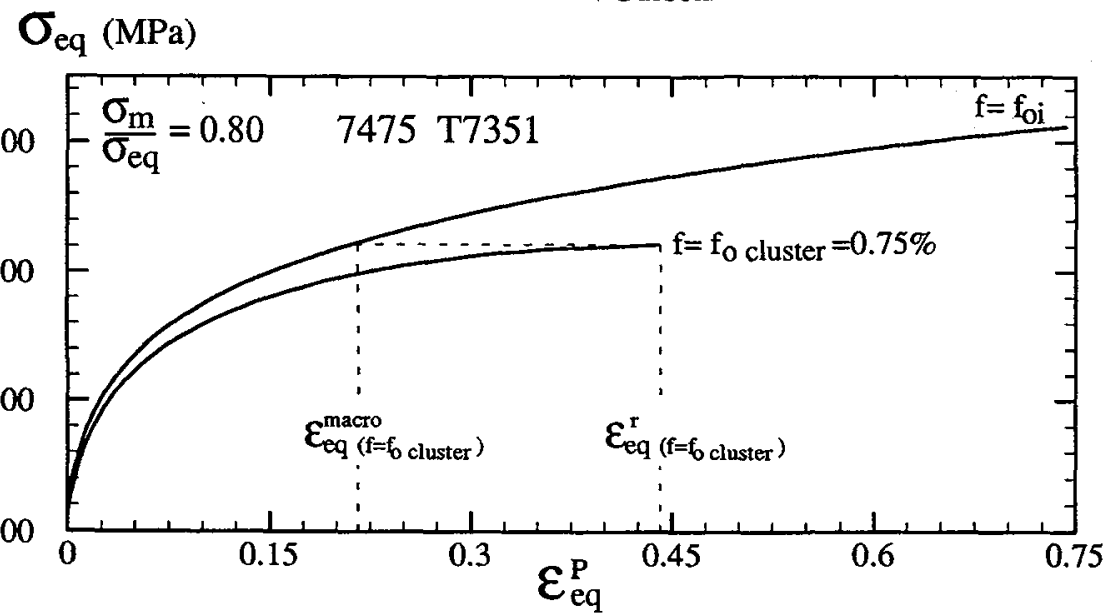

Figure 5: Sketch illustrating the softening effect associated with the growth of cavities.

Metallographical and fractographic observations showed that ductile fracture was initiated in our materials from the clusters of particles similar to those observed in Fig.1 and analyzed in Fig.2. This suggests that the mean volume fraction of clusters, $f_{0}$ cluster, as defined previously (Table 4 ) might be the relevant microstructural parameter to describe the softening effect depicted in Fig.5. In this analysis $f_{0}$ cluster was taken as the value measured in a plane perpendicular to the tensile axis. Fig. 6 shows that this analysis provides satisfactory results for both materials tested along the three main directions, when they are given the T6 and T7 heat treatments. On the other hand, in the T 3 condition, it is observed that the values of $\mathrm{f}$ predicted from the above model are larger than those measured. This difference is especially pronounced in the 7475 alloy tested in the $\mathrm{L}$ and $\mathrm{T}$ directions. It is believed that this effect is related to the formation of shear fracture mode which was observed in all types of specimens when the materials were tested in $\mathrm{T} 3$ condition, except along the $\mathrm{S}$ direction.
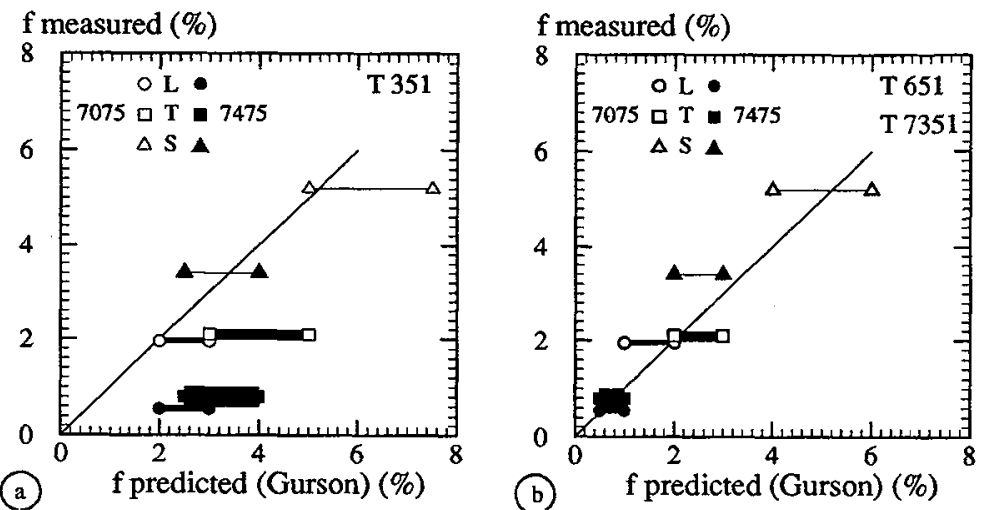

Figure 6: Comparison between the predicted and the measured values for critical volume fraction of cavities necessary to produce fracture of notched specimens. a) $\mathrm{T} 3$ condition; b) T6 and $\mathrm{T} 7$ conditions. 


\section{- Fracture toughness}

At the crack tip, as in many models based on local criteria, it is necessary to introduce a characteristic distance, $\lambda$ (For a review, see eg [13]). In the present study the above results suggest that this characteristic distance can be taken as the mean distance between the clusters in the fracture plane of CT specimens. In addition, a relationship established formerly for predicting the fracture toughness under small scale yielding conditions was used $[4,5,8]$. This relationship can be written as :

$$
\mathrm{J}_{\mathrm{IC}}=\gamma \mathrm{M} \mathrm{R}_{\mathrm{p}_{0.2}} \lambda \operatorname{Ln}\left(\mathrm{R} / \mathrm{R}_{\mathrm{O}}\right) \mathrm{c}
$$

where $\gamma$ is a numerical constant independent of the material and heat treatment. This constant $\gamma$ was taken as equal to 1.85. In Eq.6, $M$ was taken as equal to the proportionality factor between $\mathrm{J}_{\mathrm{IC}}$ and the crack tip opening displacement, $\delta_{\mathrm{c}}$, i.e. :

$$
\mathrm{M}=\mathrm{J}_{\mathrm{IC}} / \mathrm{R}_{\mathrm{p}_{0.2}} \cdot \delta_{\mathrm{c}}
$$

The value of $\mathrm{M}$ was taken from the numerical study by Mc.MeeKing [23], i.e.:

$$
\frac{1}{M}=0.54(1+n)\left[\frac{2}{\sqrt{3}}(1+v)\left(\frac{1+n}{n}\right) \frac{R_{p 0.2}}{E}\right]^{n}
$$

The values of $\mathrm{J}_{\mathrm{IC}}$ inferred from this model are compared to the experimental results in Fig.7. In Eq.6 the values of $\left(R / R_{0}\right)_{C}$ measured from experiments on notched specimens tested along the loading direction of CT specimens (Table 5), and those of the yield strength (Table 2) and work-hardening exponent, $n$, measured in the same orientation were introduced. In Fig.7, we have drawn straight lines corresponding to deviations of $\pm 10 \%, \pm 20 \%$, and $\pm 50 \%$ in terms of $\mathrm{K}_{\mathrm{IC}}$. These results show a good agreement between the predicted and the experimental values of $\mathrm{J}_{\mathrm{IC}}$, in particular in the $\mathrm{T} 6$ and $\mathrm{T} 7$ conditions where a deviation of less than about $20 \%$ (in terms of $\mathrm{K}_{\mathrm{IC}}$ ) is observed. The model tends to slightly overpredict the values of $\mathrm{J}_{\mathrm{IC}}$ for the 7475 alloy and to slightly underpredict these values for the 7075 alloy.
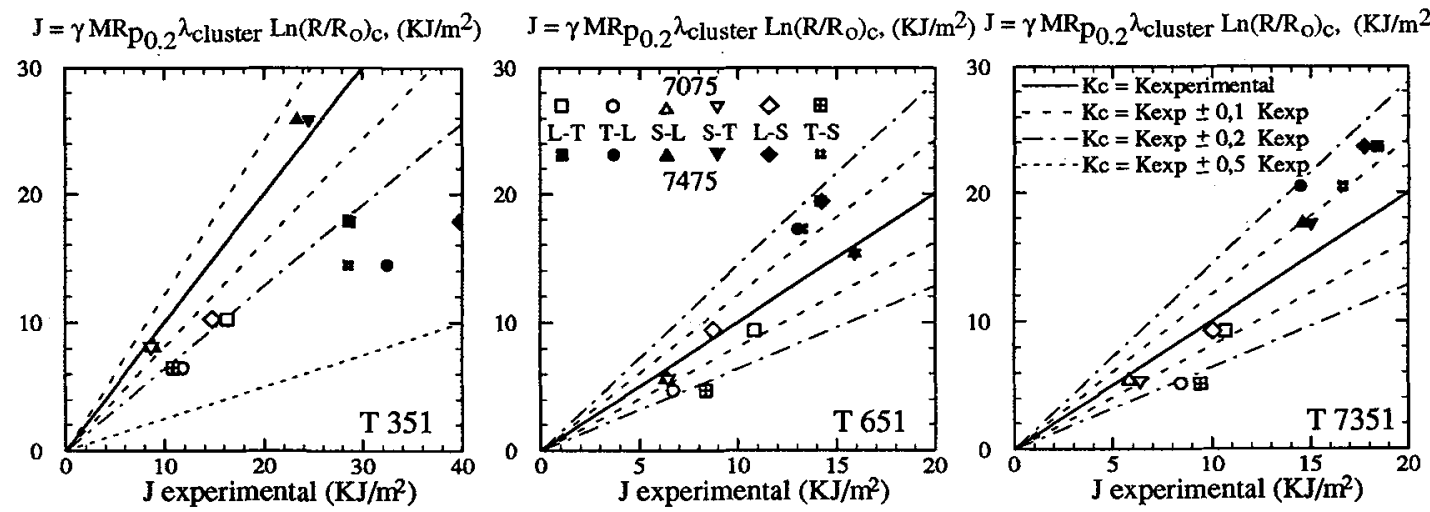

Figure 7: Comparison between the predicted and the experimental values of JIC. Alloys 7075 and 7475 tested in 3 conditions. a) $\mathrm{T} 3$, b) $\mathrm{T} 6, \mathrm{c}) \mathrm{T} 7$.

In the T3 condition the agreement between theory and experiments is much less satisfactory. This situation is likely related to the low values of $\left(R / R_{0}\right) c$ introduced in the model (Eq.6). It is well to remember that these low values result from the shear fracture mode observed in this condition. This is the reason why the model presented in the above section was used to evaluate the ductility and therefore the value of $(\mathrm{R} / \mathrm{Ro}) \mathrm{c}$ in these specimens assuming that the fracture mode was "standard" and not shear 
controlled which is a situation more appropriate to the fracture mechanisms of CT specimens. The values of the ductility predictec from this model applied, for instance, to 7475 alloy tested in the longitudinal direction are shown in Fig.8a for various values of the volume fraction of cavities. The data points indicated in this figure correspond to the experimental results. The values for the volume fraction of clusters given in Table 4 were used to predict the "standard" value for (R/Ro)c. These predicted values for $(R / R o) c$ are given in Table 5 in brackets. The results reported in Fig. $8 b$ clearly show a much better agreement between the model and the experiments when these values of the critical void growth rate are used. This strongly reinforces the validity of the model.
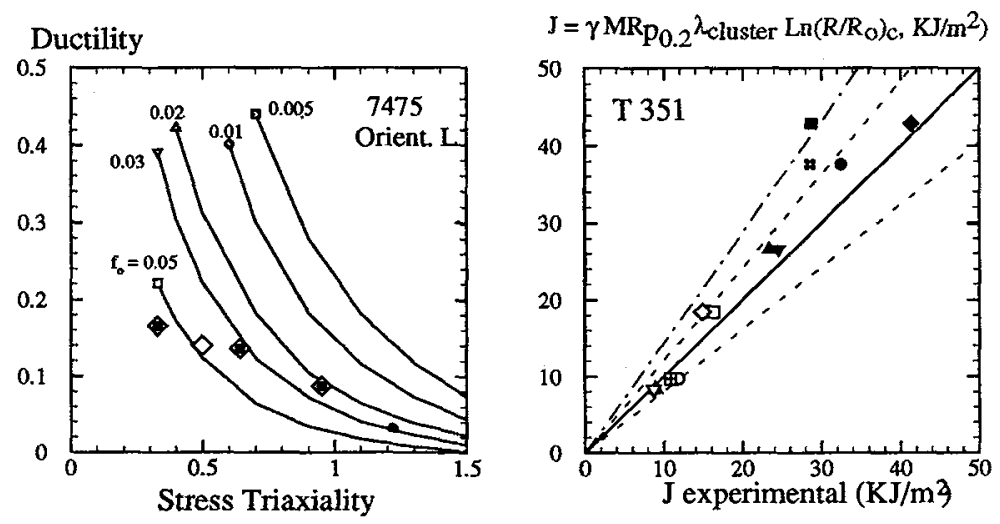

Figure 8: Alloys 7075 and 7475 T3 condition. a) Alloy 7475 . Theoretical and experimental variation of ductility with stress triaxiality ratio; b) Comparison between the predicted and the experimental values of $J_{I C}$.

\section{CONCLUSIONS}

1. It is confirmed that large intermetallic $\left(\mathrm{Mg}_{2} \mathrm{Si}\right.$ and $\mathrm{Fe}$-rich) particles play a dominant role in ductile rupture of $\mathrm{Al}-\mathrm{Zn}-\mathrm{Mg}-\mathrm{Cu}$ alloys.

2. The ductility of notched specimens can simply be interpreted in terms of critical void growth rate, $\left(\mathrm{R} / \mathrm{R}_{\mathrm{O}}\right)_{c}$, calculated from Rice and Tracey expression only when shear fracture is not predominant.

3. The low values of $\left(R / R_{0}\right)_{c}$ calculated from tests on notched specimens can be explained through a model based on Gurson potential in which the initial volume fraction occupied by the clusters of second phase particles is introduced.

4) Large variations in fracture toughness have been measured depending of the heat treatment conditions and of the orientation of the specimens. A simple model based on the local approach to ductile fracture is proposed to account for these variations.

\section{ACKNOWLEDGEMENTS}

The authors would like to acknowledge financial support from Pechiney. 


\section{REFERENCES}

[1] Hahn G.T. and Rosenfield A.R., Metall.Trans. 6A (1975) 653-668.

[2] Chen C.Q. and Knott J.F. Metal Science 15 (1981) 357-363.

[3] Lacroix J.Y. and Macé R., Mem. Scient. Revue Metallurgie (1985) 213-221.

[4] Mudry F., "Etude de la rupture ductile et de la rupture par clivage d'aciers faiblement alliés", Thesis (1982).

[5] Mudry F., Di Rienzo F. and Pineau A., "Non Linear Fracture of Mechanics vol. II - Elastic - Plastic Fracture" ASTM STP 995, Eds Landes J.D., Saxena A. and Merkle J.G. (1989) pp.24-39.

[6] Rousselier G., Nuclear Engineering and Design 105 (1987), 97-111.

[7] Pineau A. and Joly P., "Defect Assessment in Components - Fundamentals and Applications" ESIS/EGF9, Eds Blauel J.G. and Schwalbe K-H. MEP (1991) pp.381-411.

[8] Pineau A., "Topics in Fracture and Fatigue" Ed. Argon A. Springer Verlag, (1992), pp.197-234.

[9] Achon Ph., "Comportement et tenacitế d'alliages d'aluminium à haute résistance" Thesis Ecole des Mines (1994).

[10] Rice J.R. and Tracey D.M., J. Mech. Phys. Solids. 17 (1969) 201-217.

[11] Mc Clintock F.A., "Plasticity aspects of fracture", Ed Liebowitz H. (1971), pp.47-225.

[12] Beremin F.M., Metall. Trans. 12A (1981) 723-731.

[13] Pineau A., "ECF 10 Structural Integrity : Experiments, Models and Applications", Eds Schwalbe K.H. and Berger C. DVM-ESIS Proceedings, (1994) pp.37-51.

[14] Achon Ph., Ehrström J.C. and Pineau A., to appear in ECF 11, Poitiers (1996).

[15] Ehrström J.C., Achon Ph., Hébert J.F. and Pineau A. to appear in ICAAS, Grenoble (1996).

[16] Tvergaard V., Int. J. Solids Struct. 18 (1982) 659.

[17] Rousselier G., "Contribution à l'étude de la rupture des métaux dans le domaine de l'élastoplasticite", Thesis Ecole Polytechnique (1979).

[18 Perrin G. and Leblond J.B., Int. J. of Plasticity 6 (1990) 667-699.

[19] Needleman A., "Theoretical and Applied Mechanics", Ed. Germain P. et al. Elsevier Science Publishers, IUTAM (1989), pp.217-240.

[20] Tvergaard V. and Needleman A. J. Mech. Phys. Solids 34 (1986) 213-241.

[21] Becker J. J. Mech. Phys. Solids 35 (1987) 577-599.

[22] Bauvineau L., Burlet H., Eripret C. and Pineau A., This Conference.

[23] Mc Meeking R.M., J. Mech. Phys. Solids 25 (1977) 357-381. 